\title{
TURBULENT PARAMETERIZATIONS FOR A OPERATIVE AIR POLLUTION MODEL IN A CONVECTIVE BOUNDARY LAYER
}

\author{
Tiziano Tirabassi, Cristina Mangia \\ Institute ISAC of CNR, Bologna, Italy
}

\begin{abstract}
Two new turbulent parameterizations for a practical short-range model evaluating groundlevel concentrations from elevated sources are presented.
\end{abstract}

\section{RESUMO}

Apresentamos duas novas parametrizações para um modelo operacional para o cálculo das concentrações ao chão por fonte alta.

\section{INTRODUCTION}

The reliability of the K-approach in air pollution modelling strongly depends on the way the wind and eddy diffusivity are determined on the basis of the turbulence structure of the PBL. Aim of this paper is to evaluate two parameterisations for the velocity and eddy diffusivity profiles in a convective atmospheric boundary layer (ABL) in a practical short-range model, which utilizes a Fickian-type formula, where the source height and mixing layer height are simple functions of the wind and eddy diffusivity profiles.

\section{THE MODEL}

The model is named VHDM (Virtual Height Source Model) is a practical model for evaluating ground level concentrations from elevated sources that applies a new Gaussian formulation [1]. The source height $\left(h_{s}\right)$ and the mixing height are expressed by simple functions of the vertical profiles of wind ( $\mathrm{u}$ ) and turbulent diffusivity (k).

In the model the cross-wind dispersion is simulated by a Gaussian term, while for the evaluation of the cross-wind integrated concentrations $\left(\mathrm{C}_{\mathrm{y}}\right)$ we have introduced two virtual source heights as:

$$
\mu_{s}=\int_{0}^{h s}\left(\frac{u k_{s}}{u_{s} k_{z}}\right)^{1 / 2} d z \quad \varsigma_{s}=\int_{0}^{h s} \frac{u}{u_{s}} d z
$$


where the subscript s indicates values at the emission height.

We have proposed to approximate the cross-wind integrated ground level concentration $\mathrm{C}_{\mathrm{y}}(\mathrm{x}, 0)$ by means of a Fickian- type formula with a source placed at the geometric average of the two virtual source heights $\mu_{s}$ and $\varsigma_{s}$ :

$$
C_{y}(x, 0)=\frac{Q}{\sqrt{\pi \cdot x \cdot u_{s} \cdot k_{s}}} e^{\left(-\varsigma_{s} \mu_{s} /\left(4 x k_{s} / u_{s}\right)\right)}
$$

\section{ABL PARAMETERIZATIONS}

We utilised the model with 2 parameterization.

The ABL model YORDAN, that is a simple two-layer model [2] is used to produce the vertical profiles of the wind and the eddy coefficient. We applied as second one the parameterizations presented in [3]:

$$
K_{z}=k w_{*} z\left(1-z / z_{i}\right)
$$

where $\mathrm{k}$ is the von Karman constant $(\mathrm{k} \sim 0.4), \mathrm{W} *$ is the convective velocity and $\mathrm{z}_{\mathrm{i}}$ is the boundary layer height.

\section{RESULTS AND CONCLUSIONS}

We have applied the model using the Copenhagen experimental data set[4]. The results are shown in the figure 1.

Preliminary results against experimental data confirm the applicability of the approach proposed with both the parameterizations and are promising for future work.

\section{REFERENCES}

[1] Tirabassi T. and Rizza U. (1994) 'Applied dispersion modelling for ground-level concentrations from elevated dources'. Atmos. Environ., Vol. 28, pp. 611-615.

[2] Yordanov D. L., Syrakov D. E., Kolarova M. P. (2003) Parameterization of PBL from the surface wind and stability class data. Proc. of NATO ARW NATO Science Series, D. Melas and D. Syrakov (eds.), Kluwer Acad. Publ., Netherlands, Vol. 30, pp. 347-364, 2003

[3] Pleim, J., Chang, J.S.. A Non-Local Closure Model for Vertical Mixing in the Convective Boundary Layer. Atmos. Environ. 26 (6), 965-981. 1992 
[4]Gryning, S.E. and Lyck, E. Atmospheric dispersion from elevated source in an urban area: comparison between tracer experiments and model calculations, J. Appl. Meteor. 23, $651-654 ; 1984$.

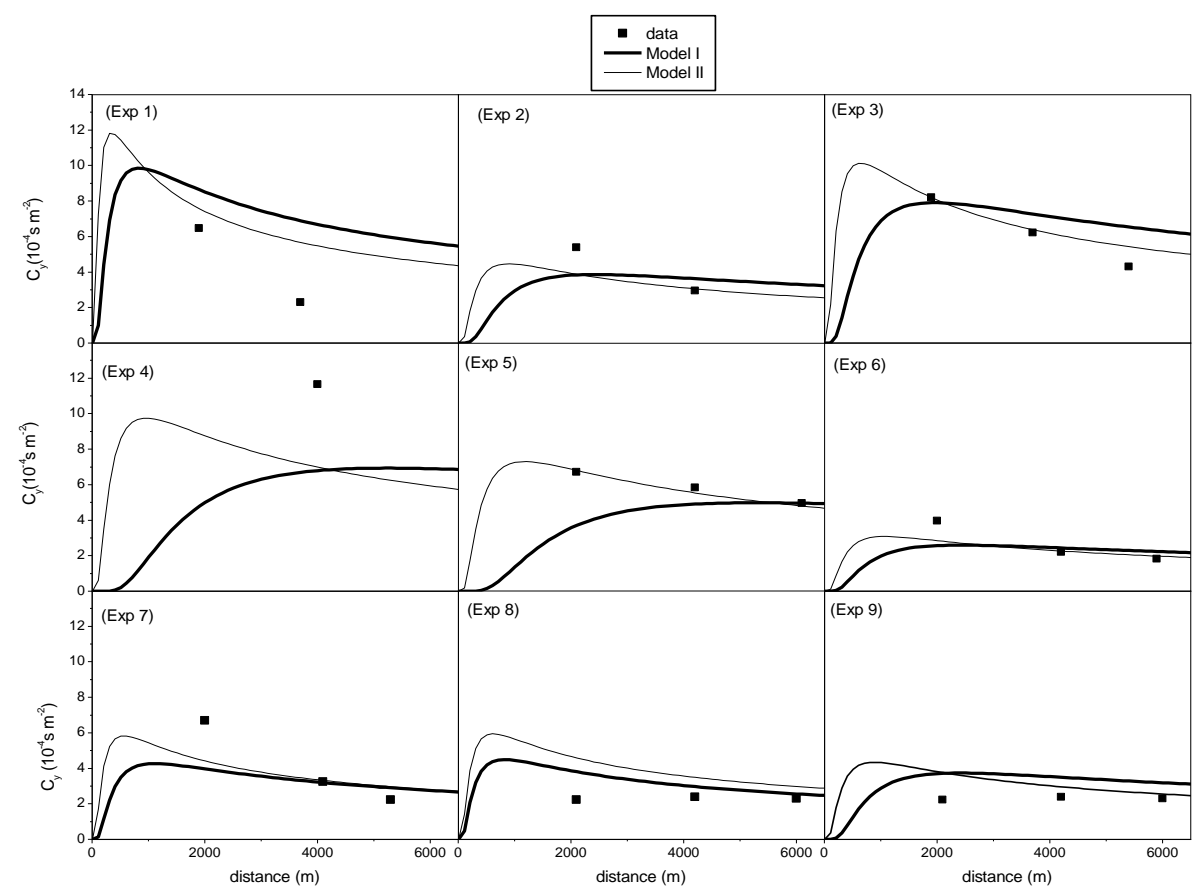

Figure 1: Profiles of potential temperature (left) and specific humidity (right) for forest (top) and pasture (bottom) sites during the day 